\title{
COLONIAL RESEARCH IN THE BRITISH COMMONWEALTH*
}

$\mathrm{T}$ HE tenth annual report of the Committee for Colonial Agricultural, Animal Health and Forestry Research records total commitments of $£ 2,042,000$ for research in this field from Colonial Development and Welfare Funds from April 1, 1946, to March 31, 1954, although new grants during the year under review amounted to only $£ 133,156$. Of the approx imately $\mathfrak{f 8}$ million available for research for the period 1955-60, $22,730,000$ has been allocated for agricultural, animal health and forestry research. With the completion of building activities and the assembly of additional specialists, research activities generally have increased, and the fruits of earlier work are now appearing with increasing frequency. Tribute is again paid to the large amount of willing assistance received from research institutions and specialists in the United Kingdom, and the collabora. tion between British and foreign specialists in tropical countries. The East African Agricultural and Forestry Research Council has been ostablished, with wide powers of control over inter-territorial research in these fields, while the work of the East African Agriculture and Forestry Research Organization on soil-moisture relations and rainfall reliability is yielding valuable results in the control of water on large catchments, forest cover and erosion control and on crop-husbandry mothods in areas of precarious rainfall. Much research into fertilizer requirements of tropical soils is proceeding, but a lot remains to be learnt about the nitrogen cycle under tropical conditions. Research in Northern Nigeria and Uganda has revealed a deficiency of sulphur in many areas which is limiting crop yields, particularly of groundnuts. The adoption of new techniques for micronutrient assessment has shown that in the Gambia and Uganda deficiencies of elements such as copper, molybdenum and boron that are required only in trace amounts may be curtailing crop yields.

Satisfactory progress has been made with soil surveys required for development plans, notably in British Honduras, Nigeria, Gold Coast, North Borneo, Aden and Somaliland. Much attention was given to cocoa, and the Cocoa Marketing Boards of Nigeria and the Gold Coast made further large grants to the West African Cacro Research Institute. The cocoa trade has accepted the very high-yielding Upper Amazon selections in West Africa as conforming to its quality requirements, so that these valuable types can now be issued to farmers, while very promising results have been obtained in breeding superior types of cacao. Research on swollen-shoot disease covered the migrations of mealybugs, which transmit the disease, the wild hosts of the virus and chemical methods for detecting latent infections. African farmers are now controlling black-pod disease of cacao in Nigeria ; but control in the Gold Coast is less satisfactory. Notable features of the work of the West African Institute for Oil Palm Research are the studies on the nutrition of the palm and on diseases due to potash and magnesium deficiencies; a substation of the Institute was opened in Sierra Leone for the study of local problems. Promising new material was discovered in New Guinea by the Banana Collecting Expedition from the Imperial College of Tropical Agriculture, Trinidad, sent out in September 1954 as part of the long and complex breeding programme directed towards combating

* Continued from p. 368. banana diseases, while the cotton-breeding work and crop-husbandry trials of the research stations maintained chiefly by the Empire Cotton Growing Corporation have yielded extremely valuable results. Among plant selections valuable to farmers singled out in the report are improved groundnuts in Nigeria and Tanganyika (where forms resistant to rosette disease have been bred), new cottons for Uganda, Nigeria and Tanganyika, sugar-canes for British Guiana, Barbados and Mauritius, better sorghums for Nigeria, Gold Coast and Tanganyika, coffee selections in East Africa, rubber resistant to South American leaf blight, and maize resistant to South American rust.

Other work emphasized in the report includes that on pepper disease in Sarawak, leaf scald on sugarcano in British Guiana, broadbean wilt in Cyprus, Alternaria leaf-spot disease of tobacco in Northern Rhodesia and Nyasaland, potato blight in the Cameroons and leaf-spot of bananas in the West Indies. The work on insect pests includes the control of coreid bugs attacking coconuts in the Solomon Islands Protectorate and Zanzibar, midges attacking millet in West Africa, rhinoceros beetles on coconuts in the Pacific area, termites in East Africa, longicorn beetles attacking cocoa in Grenada, aphis transmission of dieback of limes in the Gold Coast, and American bollworm on cotton in Tanganyika. Steady progress is being made with the Floras of Tropical East Africa, West Tropical Africa and Malaya, and preliminary work has been started on new Floras for Cyprus and the Central African region ("Flora Zambesiaca").

Veterinary research has been concerned particularly with the production of safe and effective vaccines for protection against rinderpest. The East African Veterinary Research Organization took over the manufacture of biologicals for the East Africa and Sudan regions during the year, and the research laboratories at Vom (Nigeria) continued to supply most of the needs of the West Africa region. Research is still needed to perfect the vaccines, and increased attention was given to tick-borne diseases, particularly East Coast fever, and to methods of tick-control on cattle, while studies on the African liver fluke and its intermediate snail host continued. At the Joint Animal Industry Division of the East African Agriculture and Forestry Research Organization and the East African Veterinary Research Organization, studies continued into the technique for measuring grassland productivity and into the accuracy of feeding trials, while studies of stock-raising on the intermediate savannas of British Guiana at the Ebini stock farm indicated deficiencies of cobalt and molybdenum as well as of phosphorus. Comparative studies in Fiji on heat tolerance in European and Zebu stock showed variations within breeds as great as between them, and in the Gold Coast, Nigeria and Northern Rhodesia investigations of cutaneous streptothricosis continued. Results are slowly emerging from the long-term animal breeding studies, and the commercial production of livestock in tsetseinfested areas with the aid of chemotherapy and controlled management and feeding was studied in Nigeria and Kenya, while studies of animal management in relation to cropping systems in African territories generally are pointing the way to moreefficient farming methods. Extended investigations into pastures for tropical and sub-tropical areas were 
made in Northern Nigeria, Kenya, Trinidad and Fiji, and the work on nodulation of legumes in Kenya is of particular interest in relation to the nitrogen in tropical soils.

Methods of forest regeneration were investigated in many territories, with particular attention to the use of non-toxic hormone preparations for killing tree-weeds in Uganda. Sylvicultural research in Cyprus for the regeneration of mountain forests and on eucalypt forests in the lowlands was extended. Forest flora was investigated in Malaya and North Borneo, and the systematic botany of the Malayan region is now associated with the larger project for a new "Flora Malasiana" progressing under Dutch auspices. Failure of natural regeneration in juniper forests in Somaliland is now attributed to microclimatic changes following over-grazing, and considerable progress was made by a research unit in West Africa in assessing damage from boring beetles in felled timber in relation to species, seasons and bark removal.

'The eighth annual report of the Colonial Insecticides, Fungicides and Herbicides Committee includes the usual account of the work of the Colonial Insecticide Research Unit at Porton, which was brought up to full strength by recruitmont of an entomologist and a physicist, although the recruitment of a suitably qualified and experienced staff for employment both at home and abroad still presents some difficulty. Nevertheless, it is expected that the nucleus of younger scientists trained in the special techniques applicable to insecticide research now being built up will, in a few years, provide a pool of experienced men capable of taking charge of new units or projects and directing investigations. At Porton, investigations on the loss of effectiveness of insecticidal deposits from aqueous suspensions applied to mud walls have shown that loss of toxicity is due to rapid adsorption of the insecticide by the mud, and a survey of soils from various parts of the world showed that red lateritic soils are most active in adsorbing insecticides. No practical mothod was found of abolishing or reducing the adsorptive propertios of Uganda soil. Studies of insecticidal surface coatings showod that the rate of loss of volatile insecticides from non-crystallizing films depends on the plasticizer urea-formaldehyde resin ratio and that the effectiveness of other synthetic resins as carriers for insecticides depends largely on the rate and extent of both hardening and permeability of the films. At the Imperial College Field Station, Selwood Park, investigations on the penetration of the insect integument by DDT solutions in lanoline showed that, in tropical application to Protophormia terraenovae, a fraction of the absorbed insecticide is taken up directly by the tissues, and experiments with oily deposits of $20-\mu$ DDT crystals on an absorbent surface have now shown that the availability of particles to walking flies decreases logarithmically as the proportion of oil in the deposit increases. Studies on the persistence of insecticide deposits on glass plates and foliage continued at Rothamsted and investigations at Long Ashton on the tenacities of copper fungicides were completed in September 1954. In April 1954 the Committee took over from the Agricultural Research Council the preparation and publication of the Abstracts and News Summaries dealing with insecticides and herbicides, and plans for the publication of Fungicide Abstracts and News Summaries were also in hand.
The research unit at Arusha continued its investigations on the control of tsetse flies and mosquitoes, and the work with experimental huts at Taveta, now concluded, has shown that dieldrin at 30-40 mgm. per sq. ft. needs renewal at six-monthly intervals, irrespective of surface, but at 70-80 mgm. per sq. $\mathrm{ft}$. persists for seventeen months on a mud and sand plaster. Extensive tests by the Insecticide Research Unit at Ilonga have shown that the main cotton pests (American bollworm and cotton aphis) can be controlled with a DDT/BHC mixture or endrin, but such control is unlikely to give profitable increases in yield on tho peasant crop until standards of local agriculture have been improved. A programme of research on the distribution and bionomics of dipterous flies in Uganda was started in September 1954, and the Committee has also assumed responsibility for chemical investigations in connexion with the Western Sokoto Malaria Control Project in Northern Nigeria. The study of the ecology and habits of Anopheles gambiae in Mauritius continued, as woll as the invostigation in Fiji of the incidence and behaviour of mosquitoes and the determination of the vectors responsible for the transmission of filariasis. Research on the use of herbicides, arboricides and defoliants in East Africa was extended, and promising results were obtained with defoliants as an aid to tsetse eradica tion. The report also directs attention to research in this field proceeding in the Colonies without the assistance of the Committee, such as that in Barbados on the control with soil insecticides of pests attacking the roots of sugar-cane, the promising results obtained in British Guiana with nicotine and chlordane sprays against Castria daedulus on coconuts, the extended campaign on the Gold Coast for control of Sesamia spp. and Busseola fusea in maize, that on the resistance of Culex fatigans to BHC in Penang, on the eradication of dhub grass (Cynodon dactylon) with sodium trichloroacetate at Samaru, Northern Nigeria, and on the control of the white stem borer (Anthores leuconotus) on coffee in Tanganyika with dieldrin.

The eighth annual report of the Colonial Economic Research Committee records studies at the West African Institute of Social and Economic Research of the working of the Niger Agricultural Project and of Gold Coast cocoa farmers' incomes with special reference to the abuse system, while the Economic Research Unit of the University College of the Gold Coast has completed the first stage of the periodical field investigations into movements of foodstuffs in the Accra region and has undertaken an economic survey of housing schemes in four main towns on behalf of the United Nations Mission. The Industries Branch of the Federal Department of Commerce in Nigeria has examined the economics of establishing fibre- and pulp-material industries, the production of gari and the operation of small craft, and the Eommission for Technical Co-operation in Africa South of the Sahara and its scientific advisory council are taking an increasing interest in promoting inter-African co-operation in social and economic rescarch.

The 'l'setse Fly and Trypanosomiasis Research Committee has decided to set up special panels to deal with chemotherapy and with cartography and to advise on personnel questions. Its report for the year ended March 31, 1955, records that the problem of staffing the East African Tsetse and Trypano- 
somiasis Research and Reclamation Organization's new laboratory at Tororo is being overcome, that the East African Governments have agreed in principle to transfer the headquarters of the Organization to the Central Trypanosomiasis Research Laboratory there and that the title of the Organization is to be changed to "The East African Trypanosomiasis Research Organization". Much attention is being given at the Shinyanga laboratory to respiration and water exchange in Glossina, and it is intended to link research on the trypanosomes as closely as possible with research on the vector. The Mariakani experiment on the use of 'Antrycide' prosalt as a prophylactic has shown that cattle treated while under attack from tsetse with injections of the pro-salt every two months for more than two years acquired a resistance both to a local and an imported strain of $T$. congolense, which persisted for eighteen months after treatment ceased, and the experiment is being repeated on a larger scale at Kiboko in co-operation with the Kenya Veterinary Department. The Lambwe Valley settlement continued satisfactorily; an investigation into the effect of the arboricide 2.4.5-T on freshly cut stumps of thicket suggests that this substance may be of practical value in preventing regeneration, and in Ankole discriminative clearing against $G$. morsitans is going well.

An information bureau has now been completed at the Kaduna laboratories of the West African Institute for Trypanosomiasis Research. The Institute has collected data on the nature and spread of human trypanosomiasis in Ogoja Province, where the disease is characterized by a rapid invasion of the central nervous system, and measurements of a considerable series of blood sedimentation-rates for active cases of sleeping sickness confirm that the mean rate is exceptionally high in this condition and that the immediate effect of treatment with 'Melarsen' is to reduce the rate by about one half. Trials carried out in Benue and Ogaja Provinces in collaboration with the Nigerian Sleeping Sickness Service indicate that 'Melarsen' is well tolerated by patients treated under dispensary conditions. Further work on the establishment of $T$. vivax in rats suggests that clean serum provides a substance which protects the trypanosome from the rat's antibodies, that the active factor is present in lipid-free serum and that it is a component of serum protein. The cyclical transmission of $T$. congolense by $G$. palpalis was being studied, but investigations on the use of the curative and prophylactic salts of 'Antrycide' have passod largely from the laboratory to the field, although some work has been done on resistance to 'Antrycide'. Trials with a dese of $1 \mathrm{mgm}$. $/ \mathrm{kgm}$. of 'Ethidium' bromide cured infections in Zebu cattle which had been produced by a blood-inoculated strain of $T$. vivax. At the Ugbobigha Field Station in Southern Nigeria, although the effects of topography and vegetation on the local distribution of the eight species of tsetse found in the vicinity of the Station was being mapped, research has been confined to $G$. palpalis and $G$. longipalpis. A pilot scheme has been initiated to assess the value of obstruction clearing as a practical measure of tsetse control. No major research into gamo or game conservation was undertaken, but the fact-finding survey of the major game species in Africa and the biological study of Thomson's gazelle in Tanganyika were nearing completion.

The annual report on fisheries research for 1954-55 of the Colonial Fisheries Advisory Committee reports that the allocation for fisheries research for 1955-60 is $£ 930,000$ and that the four vacancies for fisheries research officers at existing research stations should be filled during the coming year. The Inter-Territorial Fisheries Research Station at Jinja, Lake Victoria, has identified twenty species of Tilapia occurring in East Africa, and, as a result of ecological investigations which led to the discovery of several species of fish that feed mainly on snails, some of these species have been introduced successfully into dams, where they can be grown together with Tilapia. Work on the ecology and physiology of snails has shown that they play a valuable part in the bio. logical economy of both large and small bodies of water. The East African Marine Fisheries Research Organization continued and expanded its work on the bottom fishes and the hydrography of the area, obtaining evidence that the stratification of the Indian Ocean in the deep waters extends right to the fringing reefs, while the data accumulated defining the water layers and changing depth of the upper thermocline between the East African coastal current and the waters of the Arabian Sea may be of very great importance in connexion with the plankton movements and the pelagic fishes. At the Joint Northern Rhodesia-Nyasaland Fresh Water Research Station the echo-sounder of the research launch Gigipat has given excellent results, and hydrological work continued, special attention being given to the productivity of coastal waters. The West African Fisheries Research Institute continued its fisheries exploration with the research vessel Cape St. Mary from Sierra Leone and the Gold Coast, and at the Freshwater Field Station at Birnin Kebbi, Northern Nigeria, a study of marine invertebrate fauna was in progress. The Fish Culture Research Station at Batu Berendam, Malacca, is expected to bo completed at the beginning of 1957, and the Fisheries Research Unit at the University of Hong Kong was at full strength.

The report of the Director of the Anti-Locust Research Centre, on locust research and control during 1954-55, again emphasizes the heavy demands on the personnel of the Geographical Section by the further increase in the area invaded by the desert locust; 1,240 reports were received from thirty-six countries, and they became considerably more extensive, owing to the greater intensity of infestation. Statistical work has been mainly concerned with the analysis of photographs of flying locusts obtained during the field-work on swarm behaviour of the desert locust. Liaison is being maintained with the regional organizations and the insecticide industry with a view of testing new techniques likely to be of value in locust control. Detailed studies have suggested that $\mathrm{BHC}$ and $\mathrm{DNC}$ in their present formula. tions are comparable in toxicity, though the action of BHC is slower. The International Red Locust Control Service continued its detailed studies of methods of quantitative assessment of locust populations, their seasonal movements and the dynamics of vegetation in the outbreak areas. The situation with regard to the red locust in the Rukwa Valley in Tanganyika caused some anxiety, and it was also very grave with regard to the desert locust; the Arabian Peninsula continued to constitute a main source of danger, and the efforts of several governments, co-ordinated by the Food and Agriculture Organization of the United Nations, were still inadequate. 
Research matters not covered by the reports of the specialist advisory bodies are relegated to a final section of the report and include the research of the African Studies Branch of the Colonial Office into problems of African administration and the noticeable expansion in the work of the Colonial Liaison Section of the Building Research Station, which nevertheless still finds it difficult to meet its present commitments. The work of the Section has included climatological studies, such as solar radiation in West Africa, the mechanism of heat transfer in building structures under tropical conditions, and the design of buildings for air-conditioning in the tropies, and a study of the fundamental causes of weathering of building materials in different climates is projected. Reference is also made to the Falkland Islands Dependencies Survey, a major task of which is topographical mapping of the Dependencies, and to the Geodetic and Topographical Surveys, where recruitment of field staff kopt level with transfers and resignations. Good progress was made with geodetic surveys, and the triangulation and photocontrol work over twenty-thousand square miles between Dar es Salaam and Jinja, in Tanganyika, and down into the Kilombero Valley, was completed as far as weather permitted.

The overseas scientific staff of the Colonial Geological Surveys was further increased from 196 to 202 , but the number of vacancies has risen to more than thirty in consequence of the desire of some territories to enlarge their geological surveys. In some territories the fundamental task of mapping has been impeded by the diversion of geologists to other duties-for example, in connexion with the Volta River project and Tema harbour. Progress in establishing eight seismographs in the Windward and Leeward Islands and Trinidad is reported. Meteorological research was again somewhat restricted by the shortage of qualified meteorologists; but establishment of a separate research section of the East African Metoorological Department was being considered and the Departmont has continued to study the artificial control of rainfall and has used cetyl alcohol successfully to reduce evaporation from reservoirs. No laboratory work was carried out on Colonial road-research problems, but the Committee on Colonial Road Research has now been appointed. A report issued by the Colonial Road Research Liaison Officer on his visit to the Caribbean area in 1954 indicates that the basic problems for research there are much the same as in other Colonial territories, with an outstanding need to develop a method of pavement design suitable for traffic and sub-soil conditions in the various territories.

\section{MECHANISM OF PHASE TRANSFORMATIONS IN METALS}

A SYMPOSIUM on the "Mechanism of Phase A Transformations in Metals" was organized by the Metal Physics Committee of the Institute of Metals and held in London at the Royal Institution on November 9 . Nucleation and growth changes were considered during the morning session, when the discussion was based on an invited review paper by Drs. H. K. Hardy and T. J. Heal and on seven contributed papers. The afternoon meeting was devoted to martensitic changes, and there were nine contributed papers, in addition to a review paper by
Drs. B. A. Bilby and J. W. Christian. Each session was introduced by a rapporteur (Dr. Hardy and Dr. R. W. Cahn), and there were fourteen speakers in the morning discussion and seventeen in the afternoon. In the circumstances, a comprehensive report is not possible in these columns, and this survey will merely mention some of the views that seemed important to me.

A pleasing feature of the symposium was the large number of speakers from abroad. Opening the morning discussion, Prof. A. Guinier (Conservatoire des Arts et Métiers, Paris) gave a masterly survey of recent work on the early stages of precipitation. He showed a series of remarkable electron micrographs (or radiographs), obtained by $\mathrm{R}$. Castaing, using a new fine electron-beam technique with very thin solid copper-aluminium specimens. The $\theta^{\prime}$ and $\theta^{\prime \prime}$ (or Guinier-Preston [2]) precipitates were clearly visible, the latter being thin platelets of length about $1 \mu$ and thickness less than $100 \mathrm{~A}$. At very high magnifications, a regular variation in the back. ground is believed to show individual GuinierPreston [1] zones. Prof. Guinier also directed attention to the distinction between Guinier-Preston zones in copper-aluminium alloys, which consist of enriched copper platelets in a uniform matrix, and those in aluminium-silver alloys, where the spherical silver-enriched regions are surrounded by silverdepleted regions of matrix. Similar 'complexes', though of different shape, are believed to occur in copper-nickel-iron and nickel-chromium-aluminium alloys, and to be responsible for 'side-band' phenomena in powder photographs.

Among the subsequent speakers concerned with pre-precipitation effects, Dr. A. Seeger (Max-Planck Institut, Stuttgart) suggested a dislocation model for the energetics of formation of Guinier-Preston [2] zones. Dr. J. Nutting (University of Cambridge) maintained the view already expressed in his paper with Mr. G. Thomas that white spots observed in electron micrographs correspond to the formation of Guinier-Preston [1] zones, and Dr. W. H. Taylor (University of Cambridge) said that M. E. Hargreaves's explanation of side-bands was essentially equivalent to that proposed by Prof. Guinier. Prof. C. S. Smith (Institute for the Study of Metals, Chicago) suggested the application of topological principles to segregates forming during the early stages of precipitation; it might be that growth of segregates occurs because an equilibrium array cannot be attained. Miss J. M. Silcock (Fulmer Research Institute) described some recent structural work, and Dr. A. Berghézan (Centre de Recherches d'Antony, France) emphasized the importance of imperfections produced by quenching or by external stresses.

Prof. G. Borelius (Kungl. Tekniska Hogskolan, Stockholm) showed that there are, after all, probably no large discrepancies between measured lattice diffusion-rates and the rates of early precipitation phenomena. He discussed the first stage of precipitation, which he called primary clustering, and which may be shown by electrical resistance measurements before detectable diffraction effects are produced. The paper given by Prof. Borelius, with Mr. L. E. Larrson, and some of his remarks, were concerned with lead-tin alloys, and Dr. O. Krisement (MaxPlanck Institut, Düsseldorf) reported further work on this system. In contrast to D. Turnbull's results, he found that a single kinetic law did not apply at all temperatures, which suggests that the spinodal curve may have some influence. Krisement's 